\title{
IMPROVING SPRAY DISTRIBUTION AND COVERAGE ON AVOCADO TREES IN LOW VOLUME, CONCENTRATE SPRAYS
}

\author{
R.E. GASKIN ${ }^{1}$, D.W.L. MANKTELOW ${ }^{2}$ and H. PAK ${ }^{3}$ \\ ${ }^{1}$ Plant Protection Chemistry ${ }_{N Z}$, PO Box 6282, Rotorua \\ ${ }^{2}$ Applied Research and Technologies Ltd, PO Box 3415, Napier \\ ${ }^{3}$ Avocado Industry Council Ltd, PO Box 16004, Tauranga
}

Corresponding author: robyn.gaskin@ppcnz.co.nz.

\begin{abstract}
Avocado trees in New Zealand orchards are planted on squares spaced 7-14 $\mathrm{m}$ apart with tree heights of up to $14 \mathrm{~m}$. Large trees present considerable difficulties with regards to pesticide application. A series of studies was undertaken on 6-8 $\mathrm{m}$ high trees to optimise formulation prescriptions for airblast application of copper sprays. Treatments included standard (up to 3000 litres/ha) and low volume (600-1000 litres/ha), concentrate spray applications applied with the addition of varying rates of an organosilicone superspreader adjuvant. Spray deposits were measured on foliage in the inner and outer sections of the lower, mid and upper tree canopies. Low volume concentrated sprays with the superspreader adjuvant added gave higher and more evenly distributed spray deposits on positions throughout the canopy than standard sprays. Three times concentrate sprays were more effective than five times concentrate sprays because of the large canopy volume of the trees. The adjuvant maximised coverage and evenness of spray deposits.
\end{abstract}

Keywords: pesticide application, superspreader adjuvant, fruit deposits, foliage deposits.

\section{INTRODUCTION}

New Zealand avocado blocks are typically planted on $7 \mathrm{~m}$ squares and as trees begin to grow together they are removed in two stages to give $7 \times 14 \mathrm{~m}$ spacings and then $14 \times 14 \mathrm{~m}$ spacings, with trees of the Hass variety typically assuming a globular form, with height in proportion to canopy spread. The tree thinning operations result in large variations in tree size and canopy density and hence, the actual canopy area on a per hectare basis. This presents considerable difficulties for growers, with regard to pesticide application. To further compound these difficulties, the upper leaf surface is moderately easy-to-wet, fruit are difficult-to-wet, the underside of leaves and flowers are very difficult-to-wet, and wettability varies throughout the season (Gaskin et al. 2005; Gaskin \& Pathan 2006).

Current industry disease management typically involves high volume (up to 6000 litres/ha on large trees) airblast applications of copper fungicides to ensure good spray coverage, 6-8 times per season. The use of such high water rates in dilute spray applications increases the risk of off-target spray drift and contamination of orchard soils due to excessive runoff of sprays. Superspreader adjuvants have been used in a variety of crops to improve spray deposits on-target. This has been achieved by concentrating sprays and applying in reduced application volumes, with the superspreading adjuvant substituting for water volume. Such gains in spraying efficiency can lead to improved profitability for growers (Gaskin et al. 2001). Superspreader adjuvants can provide benefits for protectant fungicides by greatly improving the retention and distribution of 
sprays on large, dense avocado canopies (Gaskin et al. 2007a) and by increasing spray coverage on difficult-to-wet avocado plant surfaces (Gaskin \& Pathan 2006). However, the inappropriate use of superspreaders (e.g. at too high a concentration or in too high a spray volume) may result in reduced deposit levels and efficacy (through spray runoff) or even crop damage (by promoting undesirable active ingredient (ai) penetration into the plant). A superspreader adjuvant was shown to be non-phytotoxic and improve spray deposits on four year old avocado trees using 3-5 times less volume than standard practice (Gaskin et al. 2003, 2004). The study reported here was a continuation of those studies, undertaken to refine prescriptions (spray volumes and adjuvant concentrations) for airblast application of concentrated copper sprays to large, dense avocado canopies. The aim was for low volume, concentrate sprays to deliver equivalent or greater deposits than conventional high volume sprays, with more even distribution throughout the canopy.

\section{METHODS}

This study was undertaken on two commercial orchards near Te Puke. One orchard had medium-sized, dense trees (5-6 m high) planted on $7 \mathrm{~m}$ row spacings and the other had large, less dense trees (7-8 m high) on $14 \mathrm{~m}$ row spacings. The study compared on-target spray deposits from a "standard", high volume spray application versus three and five times concentrate sprays with the addition of different rates $(0,150,170$ or $250 \mathrm{ml} / \mathrm{ha}$ ) of Du-Wett superspreader surfactant (DW; Elliott Technologies Ltd). The adjuvant rates and concentrate spray volumes used in this study were selected on the basis of previous results (Gaskin \& Pathan 2006; Gaskin et al. 2004; R.E. Gaskin, unpubl. data) as the most likely options to improve spray coverage on tree canopies. In particular, the effect of the superspreader adjuvant, in increasing droplet spread on avocado plant surfaces, was taken into account to maximise surface coverage of leaves and minimise spray runoff (Gaskin \& Pathan 2006). The standard application volume used on large trees (2200 litres/ha) was less than for medium trees (3000 litres/ha) because spray volume was determined on the basis of tree density (Manktelow \& May 2006); large trees were more open and had less canopy (per hectare) than medium trees because the latter had still to undergo thinning operations to remove some trees. The rate of adjuvant used on large trees was selected to be similar in concentration $(\% \mathrm{v} / \mathrm{v})$ to one each of the $3 \mathrm{x}$ and $5 \mathrm{x}$ concentrate treatments (Table 1 ).

All treatments contained copper hydroxide (Kocide $2000 \mathrm{LF}, 1.08 \mathrm{~kg}$ ai/ha), with the addition of tartrazine food dye (approx. $1 \mathrm{~kg} / \mathrm{ha}$; Hawkins Watts Ltd) as a tracer. The airblast sprayer used was a Croplands 2000 Cropliner axial fan airblast set up for single sided spraying, with a Hercules volute to direct the air output into the tops of the trees. The volute was fitted with three Massotti gun nozzles, of which two were used, with different tip sizes and pressures used to adjust output volumes. The main spray ring on the sprayer was fitted with Spraying Systems D series cone nozzles for the high volume applications, and with Spraying Systems hollow cone TX nozzles for the low volume applications. Treatments were applied to two replicate plots allocated within large orchard blocks (containing at least six rows of 22 trees) in a completely randomised design. Each plot consisted of a row of four trees, running N-S, which were sprayed from both sides of the row. Buffers of at least one row of trees existed between each treatment. The inner two trees in each plot were sampled as replicates. Treatments on the two orchards were applied on separate days.

As soon as spray deposits had dried, bulked leaf samples (eight leaves per sample, two from each of side of the tree) were taken from six canopy zones on each of the medium and large sized trees. Sample zones in each case were the inner and outer canopy from lower (up to $3 \mathrm{~m})$, mid $(3-4.5 \mathrm{~m})$ and upper $(5-8 \mathrm{~m})$ tree height zones. Outer canopy was that fully exposed to the sprayer and inner canopy was clearly shielded from the sprayer by a layer of dense, outer foliage. Samples were collected into re-sealable plastic bags. They were stored at $4^{\circ} \mathrm{C}$ until washed, in 500-600 ml distilled water, within 24 $\mathrm{h}$ of spray application. Leaf areas were determined using a Leaf Area Meter (Licor). Tartrazine dye deposits were quantified spectrophotometrically $(427 \mathrm{~nm})$, where dye $(\mathrm{mg} / \mathrm{ml})=0.0217^{*}$ absorbance $\left(\mathrm{R}^{2}=0.999\right)$. 
Deposits were calculated as dose applied $\left(\mu \mathrm{g} / \mathrm{cm}^{2}\right)$. All results were normalised at $1 \mathrm{~kg} / \mathrm{ha}$ dye application and data were analysed as a randomised block design, using analysis of variance and least significant difference test (LSD) at $\mathrm{P}=0.05$, to determine the significance of treatment and canopy position on spray deposits retained by foliage.

\section{RESULTS AND DISCUSSION}

The main effect of treatment on deposits was highly significant $(\mathrm{P}<0.001$, Table 1$)$, as was the interaction of treatment with canopy position $(\mathrm{P}<0.001$, Table 2$)$. Mean deposits from the $3 \mathrm{x}$ concentrate $(+\mathrm{DW})$ treatments $($ Table 1$)$ were higher $(\mathrm{P}<0.05)$ than the standard on both medium and large trees, and higher than $5 \mathrm{x}$ concentrate deposits on medium trees. On large trees, the $3 x$ concentrate mean deposits (both +/- DW) were equivalent (Table 1). While the adjuvant had no effect on total deposits in this instance, the evenness of coverage of leaf surfaces, particularly on the very difficult-to-wet underside, was visibly improved (Fig. 1). This was in accord with the ability of DW to increase the spread and coverage of pesticide spray droplets deposited on avocado foliage (Gaskin \& Pathan 2006).

\section{TABLE 1: Retention of sprays $\left(\mu \mathrm{g} / \mathrm{cm}^{2}\right.$; normalised for $1 \mathrm{~kg}$ dye/ha) on avocado foliage with varying spray volumes and adjuvant rates, for medium and large trees.}

\begin{tabular}{|c|c|c|c|c|c|}
\hline $\begin{array}{l}\text { Mean tree } \\
\text { height }(\mathrm{m})\end{array}$ & $\begin{array}{c}\text { Spray } \\
\text { volume } \\
\text { (litres/ha) }\end{array}$ & $\begin{array}{c}\text { Fungicide } \\
\text { concentration }\end{array}$ & $\begin{array}{c}\text { DW adjuvant } \\
\mathrm{ml} / \mathrm{ha}(\%)\end{array}$ & Treatment code & $\begin{array}{c}\text { Mean } \\
\text { deposits }\end{array}$ \\
\hline \multicolumn{6}{|l|}{ Medium } \\
\hline 5.6 & 3000 & std & 0 & std medium & $1.10 \mathrm{~d}^{1}$ \\
\hline 6.1 & 1000 & $3 \mathrm{x}$ std & $150(0.015)$ & $3 x+D W 150$ & $1.48 \mathrm{~b}$ \\
\hline 6.1 & 1000 & $3 \mathrm{x}$ std & $250(0.025)$ & $3 x+D W 250$ & $1.51 \mathrm{~b}$ \\
\hline 6.0 & 600 & $5 \mathrm{x}$ std & 0 & $5 \mathrm{x}$ med & $1.21 \mathrm{~cd}$ \\
\hline 5.8 & 600 & $5 \mathrm{x}$ std & $150(0.025)$ & $5 x+$ DW 150 & $1.41 \mathrm{bc}$ \\
\hline 6.1 & 600 & $5 \mathrm{x}$ std & $250(0.042)$ & $5 x+$ DW 250 & $1.24 \mathrm{~cd}$ \\
\hline \multicolumn{6}{|l|}{ Large } \\
\hline 7.0 & 2200 & std & 0 & std large & $1.49 \mathrm{~b}$ \\
\hline 7.6 & 730 & $3 x$ std & 0 & $3 x$ large & $1.92 \mathrm{a}$ \\
\hline 8.1 & 730 & $3 x$ std & $170(0.023)$ & $3 x+$ DW 170 & $1.90 \mathrm{a}$ \\
\hline
\end{tabular}

${ }^{1}$ Means sharing common letters are not significantly different $(\mathrm{LSD}, \mathrm{P}<0.05)$

Mean deposits on the foliage of large trees were greater than on medium trees (Table 1), highlighting the need to make adjustments to spray volumes and chemical rates in light of tree size and density. Applying the same spray volume to all trees is likely to result in over-wetting and runoff from less dense canopies. On dense, mediumsized trees, the outer canopy deposits tended to be greater than inner, often by $>50 \%$ (Table 2; $\mathrm{P}<0.001$ ), particularly on the upper and lower canopy with $5 \mathrm{x}$ concentrate sprays. This is typical of inner versus outer canopy deposit ratios for many tree crops (Manktelow et al. 2004) and indicates the difficulty of delivering sprays evenly to these canopies. The $3 \mathrm{x}$ concentrate $(+\mathrm{DW})$ sprays were the most evenly distributed and their inner and outer canopy spray deposits were generally similar (Table 2). Overall, the $3 x$ concentrate sprays performed better than the $5 x$ concentrate sprays because the extra spray volume covered the large canopy volume better. High spray volumes alone do not lead to higher deposits, as evidenced by the performance of the standard spray (Table 2). A tree canopy requires a minimum volume of spray to cover all foliage 
surfaces but this volume can be reduced significantly with the addition of a superspreader adjuvant such as DW. In pipfruit, for example, low volume (6-8x concentrate) sprays containing DW, provided equivalent disease control and export packouts compared to standard programmes (Gaskin et al. 2007b). However, the density and size of an avocado canopy is far greater than an apple canopy and more spray volume is required to achieve coverage of all avocado plant surfaces. On medium-sized trees, deposits on mid canopy $\geq$ lower $>$ upper sections $(\mathrm{P}<0.001)$. Targeting dense avocado trees with pesticide sprays is a difficult task and the upper and inner canopies are the most difficult targets. The deposits from $3 x$ concentrate $(+\mathrm{DW})$ treatments were at least equivalent to and more consistent than for the standard and the $5 \mathrm{x}$ concentrate treatments (Table 2). The $3 \mathrm{x}$ concentrate sprays will likely be more beneficial than $5 \mathrm{x}$ concentrate sprays for this crop, using current spray application technology.

In large trees, the target for sprays was the mid and upper tree sections because the lower canopy bears little fruit. As a result, mid and upper sections received similar deposits and more than the lower canopy (Table 2). Because pruning and branch attrition had reduced canopy density in the lower section, the inner foliage received proportionally higher deposits, compared to outer. While large trees look like a formidable target because of their height and width, they are actually easier to target than dense medium sized trees with a well set-up sprayer. A similar study undertaken on fruit (data not presented) confirmed the results on foliage. The application of concentrate sprays would provide substantial gains in work rate efficiency for avocado growers; they provided equivalent, and often higher, deposits than standard high volume sprays.

The superspreader adjuvant had no effect on mean deposits on trees (Table 1) but it provided a more consistent distribution of concentrate spray deposits throughout the canopy (Table 2). Adjuvant addition is essential to maximise the evenness of coverage of sprays on difficult-to-wet plant surfaces (Fig. 1) when total spray volume is reduced. The addition of DW to sprays is recommended at approximately $200 \mathrm{ml} / \mathrm{ha}$ (or $0.025 \%$ concentration) to optimise spray coverage and minimise adjuvant cost to growers, but this will be dependent on the pesticide product(s) and amount(s) included in the spray (Gaskin \& Pathan 2006).

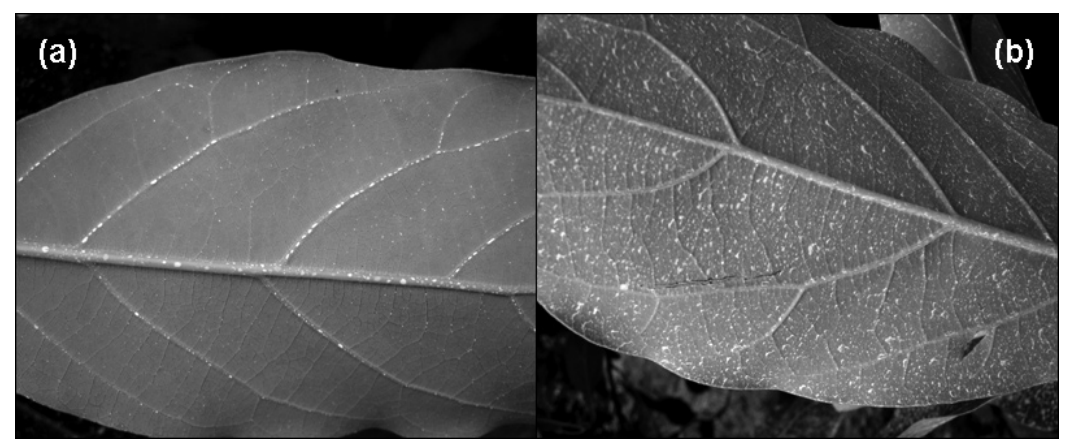

FIGURE 1: Abaxial surface of avocado leaf sprayed with (a) standard application (3000 litres/ha) with no additional adjuvant or (b) 3x concentrate (1000 litres/ha) plus DW adjuvant $(250 \mathrm{ml} / \mathrm{ha})$. 
TABLE 2: Retention of sprays $\left(\mu \mathrm{g} / \mathrm{cm}^{2}\right.$; normalised for $\left.1 \mathrm{~kg} \mathrm{dye} / \mathrm{ha}\right)$ on avocado foliage in different canopy positions with varying spray volumes and adjuvant rates, for medium and large trees.

\begin{tabular}{lcccccc}
\hline & \multicolumn{7}{c}{ Canopy position } \\
\cline { 2 - 7 } Treatment code & $\begin{array}{c}\text { Upper } \\
\text { inner }\end{array}$ & $\begin{array}{c}\text { Upper } \\
\text { outer }\end{array}$ & $\begin{array}{c}\text { Mid } \\
\text { inner }\end{array}$ & $\begin{array}{c}\text { Mid } \\
\text { outer }\end{array}$ & $\begin{array}{c}\text { Lower } \\
\text { inner }\end{array}$ & $\begin{array}{c}\text { Lower } \\
\text { outer }\end{array}$ \\
\hline Medium trees & 0.35 & 1.17 & 1.00 & 1.66 & 1.00 & 1.40 \\
std medium & 0.72 & 1.45 & 1.47 & 1.81 & 1.45 & 1.96 \\
3x + DW150 & 1.15 & 1.43 & 1.57 & 1.76 & 1.50 & 1.65 \\
3x + DW250 & 0.38 & 1.53 & 1.10 & 1.51 & 0.81 & 1.96 \\
5x medium & 0.80 & 1.76 & 1.09 & 2.05 & 0.83 & 1.91 \\
5x + DW 150 & 0.59 & 1.37 & 1.11 & 1.67 & 1.02 & 1.71 \\
5x + DW 250 & & & & & & \\
Large trees & 1.78 & 2.06 & 1.58 & 2.36 & 0.55 & 0.64 \\
std large & 1.63 & 2.53 & 1.46 & 3.51 & 1.24 & 1.18 \\
3x large & 1.96 & 2.64 & 1.97 & 2.75 & 1.55 & 0.55 \\
3x + DW 170 & \multicolumn{7}{c}{0.54} \\
LSD (P<0.05) & \multicolumn{7}{c}{} \\
\cline { 2 - 7 }
\end{tabular}

\section{CONCLUSIONS}

Concentrating pesticide in low volume (3x concentrate) airblast sprays using superspreader adjuvant technology improved the distribution and coverage of copper sprays applied to avocado trees relative to standard high volume sprays. Deposits in different canopy zones showed less variability with the $3 x$ concentrate plus adjuvant treatment than those from standard high volume and $5 \mathrm{x}$ concentrate sprays. While surface coverage was not quantitatively assessed, the use of concentrate plus adjuvant applications was observed to provide more even coverage of leaf and fruit surfaces than standard high volume applications. These results are expected to result in improved efficacy from $3 \mathrm{x}$ concentrate applications.

\section{ACKNOWLEDGEMENTS}

Thanks to R\&S Bailey and J Crozier for the use of their orchards and equipment, and to S Saunders who provided a sprayer. Technical assistance was provided by K Steele, R van Leeuwen, A Pathan, C Moore, WA Forster, W May, G May and D Crozier. Chemicals were provided by Elliott Technologies Ltd. The project was funded by the MAF Sustainable Farming Fund and the NZ Avocado Growers Association. Part of this study was reported in a poster presented at the 2007 International Symposium on Adjuvants for Agrochemicals, Columbus, Ohio, USA.

\section{REFERENCES}

Gaskin RE, Pathan AK 2006. Characterising plant surfaces and adjuvant interactions to improve pesticide spray retention and coverage on avocados. New Zealand Avocado Growers' Association Annual Research Report 6: 63-70. http://www. avocadosource.com/

Gaskin RE, Manktelow DWL, Pak H 2007a. Use of adjuvant technology to improve the distribution of copper sprays on avocado canopies. Proceedings of the $8^{\text {th }}$ International Symposium on Adjuvants for Agrochemicals, Columbus, Ohio, USA, 6-9 August 2007, Poster abstract 08 [ISBN 978-0-473-12388-8].

Gaskin RE, Manktelow DWL, Geelen A 2007b. Adjuvant-enhanced, low volume spray programmes for pipfruit. Proceedings of the $8^{\text {th }}$ International Symposium on Adjuvants for Agrochemicals, Columbus, Ohio, USA, 6-9 August 2007, 8 pp. [ISBN 978-0-473-12388-8]. 
Gaskin RE, Steele KD, Forster WA 2005. Characterising plant surfaces for spray adhesion and retention. New Zealand Plant Protection 58: 179-183.

Gaskin RE, Manktelow DWL, Skinner SJ, Elliott GS 2004. Use of a superspreader adjuvant to reduce spray application volumes on avocados. New Zealand Plant Protection 57: 266-270.

Gaskin RE, Hofstee ME, Elliott GS 2003. Phytotoxicity of agrochemical adjuvants on avocados. New Zealand Plant Protection 56: 274.

Gaskin RE, Murray RJ, Steele KD, Stevenson AH 2001. Organosilicone surfactant reduces pesticide spray in kiwifruit orchards. Proceedings of the $6^{\text {th }}$ International Symposium on Adjuvants for Agrochemicals, Amsterdam, 13-17 August 2001. Pp. 191-196.

Manktelow DWL, Gurnsey SJ, MacGregor AM 2004. Deposit variability and prediction in fruit crops: What use are label rates anyway? In: International Advances in Pesticide Application. Aspects of Applied Biology 71: 269-278.

Manktelow DWL, May W 2006. Review: Determining and optimising chemical application rates and spray application in different avocado canopies. New Zealand Avocado Growers' Association Annual Research Report 6: 71-80. http://www. avocadosource.com/ 